\title{
Effects of partner novelty on affiliation in the rat
}

\author{
JOHN C. BAREFOOT \\ Carleton University, Ottawa, Canada K1S 5B6 \\ WAYNE P. ASPEY \\ Dartmouth College, Hanover, New Hampshire 03755 \\ and \\ JAMES M. OLSON \\ Carleton University, Ottawa, Canada K1S 5B6
}

\begin{abstract}
Three experiments explored the relationship between novelty and affiliation in rats. In Experiment I rats housed either alone or in pairs were tested for 5 consecutive days with either the same partner or a stranger each day. Partner novelty led to more mutual approach than did familiarity, but only among individually housed animals. However, a sampling difference existed between one of the paired-housed groups and the other animals. Therefore, only paired-housed animals were used in a second experiment employing the same procedure. Familiar rat pairs affiliated less than did pairs of strangers. In Experiment III, rats run for 1 day with a stranger again showed more mutual approach than did pairs of cagemates. The results suggest that rats discriminate between individual conspecifics in making affiliative choices and that their choices are based on a preference for novelty.
\end{abstract}

There is a growing body of experimental support for Zajonc's (1968) "mere exposure" hypothesis, which states that familiarity is a sufficient condition for the development of attraction to a stimulus. Most of these studies have employed human subjects, but Zajonc (1971) has suggested that the phenomenon may be an important process in the development of social attachments in other species as well. While there are a number of studies of nonhumans which have found a preference for familiar conspecifics (e.g., Pratt \& Sackett, 1967), this principle has not been demonstrated in rats. In fact, Latané, Schneider, Waring, and Zweigenhaft (1971) found no difference in the level of affiliation in rat pairs composed of familiar or unfamiliar testing partners. The first experiment reported below is an attempt to further test the effects of familiarity on affiliation in rats and employs the same procedure as the Latane et al. (1971) study. Affiliation was defined as the degree of mutual approach between two rats placed in a circular open field. Animals were housed either alone or in pairs and the degree of familiarity between testing partners was manipulated by testing animals with a different partner each test day, the same partner, or with their cagemate.

The second author is now at the University of Texas Medical Branch at Galveston. Reprint requests should be sent to John C. Barefoot, Department of Psychology, Carleton University, Ottawa, Ontario, Canada. This paper is sponsored by W. L. Croll, who takes full editorial responsibility for its contents.

\section{EXPERIMENT I}

\section{Method}

Subjects. Fifty-two experimentally naive male Holtzman Sprague-Dawley albino rats arrived in the laboratory at 30 days of age. Upon arrival, 32 rats were housed individually in hanging metal cages $25.4 \times 17.8 \times 17.8 \mathrm{~cm}$ with wire mesh fronts and bottoms, and the remaining 20 rats were housed in pairs in identical cages. All subjects were handled 1 min daily for 2 weeks prior to testing, which began when they were 45 days old. They were maintained on ad-lib food and water schedules and a 24-h light condition throughout the experiment. Animals in the PD condition (described below) came from a separate shipment that arrived 2 months after the testing of the other groups.

Apparatus. The testing apparatus was a circular open field $122 \mathrm{~cm}$ in diam, surrounded by a $45.7-\mathrm{cm}$ wall. The field was painted flat black with white lines marking the floor into 49 numbered sections of equal area (Latané, 1969) and was illuminated from $2.13 \mathrm{~m}$ above by a $100-\mathrm{W}$ bulb behind a frosted glass shield.

Procedure. Each rat was placed in the open field for a 6-min testing session, alternately either alone or with another rat. ${ }^{1}$ The order of testing and testing condition (alone or together) was counterbalanced over days for all groups. While subjects moved about the open field, the experimenter recorded the location of each rat at 10 -sec intervals. The field was cleaned with a damp sponge at the end of each testing session.

Two measures of affiliation were computed. The distance measure was the mean distance between animals over the 36 observations in each session. The contact score consisted of the number of times the animals were in the same section of the maze when the observations were recorded.

Experimental Conditions. The following five experimental groups were employed: (a) $\mathrm{PM}=$ paired-housed rats tested with their cagemate $(n=$ five pairs); (b) $P S=$ paired-housed rats tested with the same noncagemate partner each session $(n=$ five pairs); (c) $P D=$ paired-housed rats tested with a different partner 


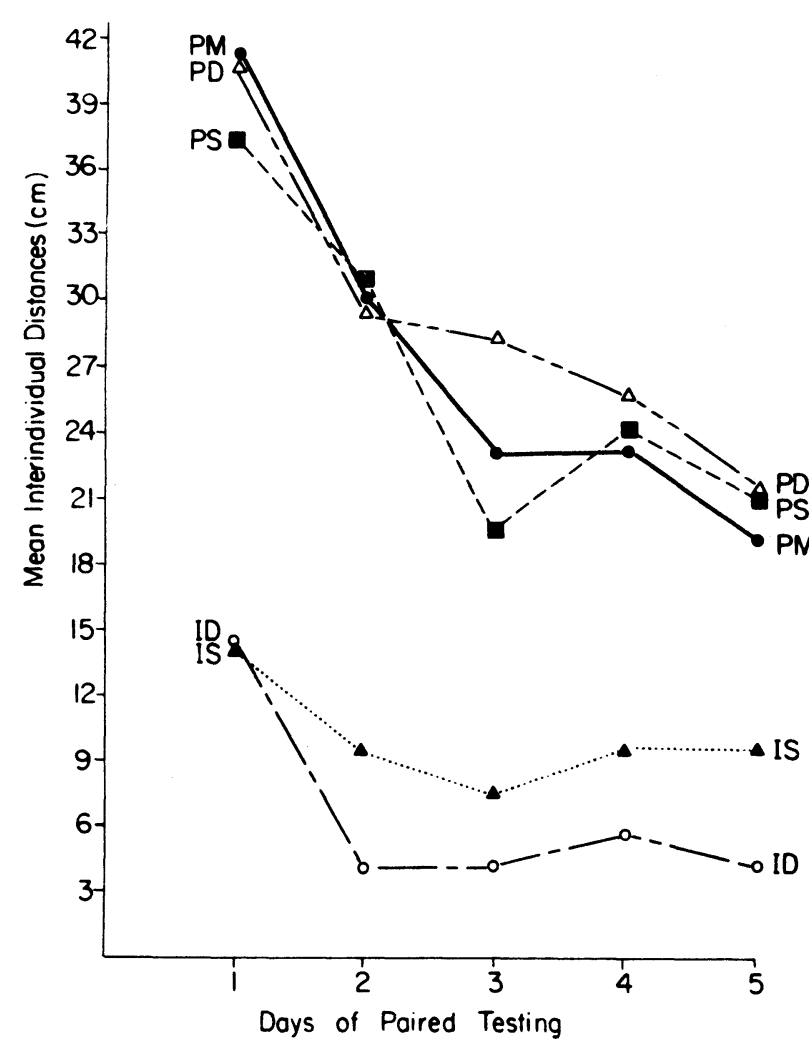

Figure 1. Mean interindividual distances between rats by novelty of testing partner and housing condition.

each session ( $\mathrm{n}=$ six pairs); (d) IS = individually housed rats tested with the same partner each session $(n=$ five pairs); and (e) ID = individually housed rats tested with a different partner each session $(n=$ five pairs $)$.

\section{Results}

Figure 1 presents the mean distance scores for all groups. There were no differences between the PM and PS groups, so the data of these two conditions have been combined for the analyses reported below.

Consistent with previous research (e.g., Sloan \& Latané, 1974), individually housed animals were more affiliative than paired-housed animals, $F(1,22)=184.7$, $\mathrm{p}<.001$, and affiliation increased over days, $\mathrm{F}(4,88)=$ $18.5, \mathrm{p}<.001$.

There was no main effect for partner novelty, but there was a marginally significant interaction of Partner Novelty by Housing Condition, $F(1,22)=3.51, p<.07$. Individually housed animals were more affiliative with novel partners than with familiar partners, but this was not true for paired-housed animals.

Analysis of the contact scores revealed a similar pattern. Individually housed animals were more affiliative than paired-housed animals, $\mathrm{F}(1,22)=260.71$, $\mathrm{p}<.001$, affiliation increased over days, $F(4,88)=$ $18.35, \mathrm{p}<.001$, and housing condition interacted with partner novelty, $\mathrm{F}(1,22)=7.04, \mathrm{p}<.02$.

\section{EXPERIMENT II}

In Experiment I rat pairs who were familiar with each other affiliated less than did pairs of strangers, but this was only true among those animals who had been housed individually. Before this interaction is accepted, however, it should be recalled that the PD group was composed of animals who arrived at the laboratory at a different time than the others. This sampling difference might have artifactually affected the affiliation of the PD group, masking any partner effect among together-housed rats. Experiment II was designed to further test for the existence of a partner novelty effect among paired-housed animals.

\section{Method}

Subjects. Forty naive male Sprague-Dawley albino rats were used. They were 5-6 weeks old upon arrival in the laboratory and were handled for $1 \mathrm{~min}$ daily for 10 days prior to testing. They were housed in pairs in hanging cages $(24 \times 20 \times 20 \mathrm{~cm})$ with wire mesh fronts and bottms. They were maintained on ad-lib food and water schedules with a 12-h light cycle.

Apparatus. Testing occurred in a square wooden open field $101.5 \times 101.5 \mathrm{~cm}$ with a $37-\mathrm{cm}$ surrounding wall. The field was painted white with black lines marking the floor into 25 equal squares $(20.3 \times 20.3 \mathrm{~cm})$ and was illuminated from $2.65 \mathrm{~m}$ above by six 40-W fluorescent bulbs behind two white frosted plastic shields.

Procedure. Rats were placed in the open field for 6 min daily for 5 consecutive days, paired with either the same or different partners. Cagemates were never paired. Measures were taken in a manner identical to that of Experiment $\mathbf{I}$.

\section{Results}

Animals paired with a familiar partner maintained a mean distance of $40.34 \mathrm{~cm}$, compared with $34.5 \mathrm{~cm}$ for the pairs of novel partners, $F(1,18)=6.57$, $p<.02$. The same effect is apparent in the contact scores. Familiar partners were in the same square an average of 11.04 observations per day, while unfamiliar partners had a mean score of $13.72, F(1,18)=20.61$, $\mathrm{p}<.001$.

Contrary to previous research, there was no significant decrease in the distance scores over time, $F(4,72)=1.02$, but this result might be due to the use of the square maze, which could have led to artifactually low distance scores in the early sessions due to the tendency for animals to corner. However, the days effect did appear in the analysis of the contact scores, $F(4,72)=9.43, p<.001$

\section{EXPERIMENT III}

The partner novelty effect in Experiment II replicated the finding with individually housed animals in Experiment I, but did so with paired-housed subjects. This result makes it appear that the failure to find a novelty effect with paired-housed animals in Experiment I was due to sampling error rather than any special effect of housing. 
Nevertheless, the possibility exists that the difference between the results in Experiment II and those of Latané et al. (1971) could be due to housing. Latané et al. tested their paired-housed subjects with their cagemates, while Experiment II never used cagemate pairings. Experiment III was an attempt to replicate the novelty effect by comparing the affiliation of novel partner pairs with that of cagemates.

\section{Method}

Subjects. Experiment III employed the same 40 animals used in Experiment II. After the completion of Experiment II, the rats (now 7-8 weeks old) were left inactive for 3 days, with their food and water supplies maintained ad lib. They were then assigned to each condition randomly, with the provision that half of the subjects from the different-partner condition of Experiment II were assigned to the cagemate condition.

Procedure. Animals were tested with their cagemate or a novel partner in the open field following the procedure of Experiment II. There was only 1 day of testing.

\section{Results}

Once again it was found that pairs of novel partners affiliate more than pairs of familiar animals. Novel pairs maintained a mean interindividual distance of $29.83 \mathrm{~cm}$, while cagemates had a mean distance of $40.96 \mathrm{~cm}, \mathrm{~F}(1,18)=4.49, \mathrm{p}<.05$. The same result occurs when the groups are compared on the basis of mean contact scores $(17.0$ vs. 11.5$), F(1,18)=18.09$, $\mathrm{p}<.001$.

\section{DISCUSSION}

Latané et al. (1971) suggested that rats do not normally discriminate between individual conspecifics in making affiliative choices. The data of the present studies contradict that notion, but the direction of the preference was unexpected. Rats do not appear to form specific attachments, but affiliative choices appear to be based on the same preference for novelty which they show in their choices of nonsocial stimuli (e.g., Glanzer, 1958).

\section{REFERENCES}

Glanzer. M. Stimulus satiation in situations without choice. Journal of Comparative and Physiological Psychology. 1458, 51. 3.32-333.

LATANÉ. B. (iregariousness and fear in laboratory rats. Journal of Experimental Social Psychology. 1469, 5, 61-69.

Latané, B. Schneider, E., Waring. P., \& ZWeigenhaft, $R$ The $>$ peciticity of social attraction in rats. Psychonomic Science. 1471. 23, 28-29.

Pratt, C. L., \& Sackett, G. P. Selection of social partners as a function of peer contact during rearing. Science. $1967,155,1133-1135$.

Sloan, L. R., \& Latane, B. Social deprivation and stimulus satiation in the albino rat. Journal of Comparative and Physiological Psychology, 1974, 87, 1148-1156.

ZAjonc, R. B. Attitudinal effects of mere exposure. Journal of Personality and Social Psychology Monograph Supplement. 1968. 9(2. Part 2), 1-27.

Zajonc. R. B. Attraction, affiliation, and attachment. In J. F. Eisenberg and W. S. Dillon (Eds.), Man and beast: Comparative social behavior. Washington. D.C: Smithsonian Institute Press. 1971.

\section{NOTE}

1. Data from alone testing sessions will not be discussed in this paper. 